\title{
Estimating the chemical composition of the soil solution of glasshouse soil. 2. Relationships between the compositions of soil solution and aqueous extracts
}

\section{J. VAN DEN ENDE}

Glasshouse Crops Research Station, P.O. Box 8, NL 2670 AA Naaldwijk, Netherlands

Received 10 May 1989; accepted 29 June 1989

\begin{abstract}
The possibilities of estimating electrical conductivities and $\mathrm{K}, \mathrm{Na}, \mathrm{Ca}, \mathrm{Mg}, \mathrm{NO}_{3}, \mathrm{Cl}$ and $\mathrm{SO}_{4}$ contents of press extracts of glasshouse soils from corresponding analytical data of saturation extracts or 1:5 by-weight extracts were examined through construction of regression equations. The analytical data of saturation and 1:5 by-weight extracts were and were not corrected by multiplication with dilution factors, being the ratios between the water contents of the soils employed to obtain the extracts and the water contents of the soils at field capacity. The dilution factors used were not derived from actual water contents but from water contents assessed on the basis of loss-on-ignition values. In a number of cases, the estimation technique could be improved through introduction of one or two extra variables, such as the dilution factor, the corrected $\mathrm{SO}_{4}$ content of the extract, the water content of the field-moist soil and the ratio between the mass fractions clay and loss-on-ignition.
\end{abstract}

Keywords: soil solution, saturation extract, 1:5 extract, glasshouse soil, electrical conductivity, nutrient elements, gypsum, loss-on-ignition, regression equation

\section{Introduction}

As is stated in the introduction of the first paper of this series (van den Ende, 1989), the investigation described was carried out to examine the possibilities of estimating the chemical composition of soil solution of glasshouse soil from both the composition of saturation extract and that of 1:5 by-weight extract. In that paper, the techniques of obtaining soil solutions and soil extracts, and of obtaining valid analytical data on ionic concentrations in soil solutions and extracts were discussed. In this second paper, regression equations are presented, with which the estimation procedure for electrical conductivity $(\mathrm{EC})$ and $\mathrm{K}, \mathrm{Na}, \mathrm{Ca}, \mathrm{Mg}, \mathrm{NO}_{3}, \mathrm{Cl}$ and $\mathrm{SO}_{4}$ contents can be evaluated. 


\section{Materials and methods}

For convenience sake, it is repeated here that (1) soil solutions and extracts were obtained from 75 different glasshouse soils varying widely in water-holding capacity and in salt and nutrient status, (2) the water contents of soils at sampling time were approximately equal to those at field capacity, (3) soil solutions (henceforth named press extracts) were obtained from field-moist soil samples by pressing, (4) saturation extracts were prepared from both field-moist and dried soil samples (extracts will be distinguished by the qualifications 'field-moist' and 'air-dry', respectively), and (5) 1:5 by-weight extracts (henceforth named 1:5 extracts) were prepared from dried soil samples, care being taken to allow for the water present in these samples.

Linear-regression equations were calculated for the relationships between the analytical data of press extracts, on the one hand, and those of saturation or 1:5 extracts, on the other. The former data were always employed in the equations as dependent variables. Prior to the calculations, the latter data were and were not multiplied by dilution factors, being the ratios of water contents of the soils at saturation and of the suspensions made for the 1:5 extracts, and the water contents of the soils at field capacity.

The purpose of the multiplying factor mentioned was to acquire higher correlation coefficients in the calculations. Such increases in correlation may especially be expected, when dilution factors are high and vary strongly among soils, in which cases the correlation coefficients found without applying a dilution factor are usually low.

The dilution factors used were not derived from actual water contents, but from water contents estimated on the basis of loss-on-ignition values (van den Ende, 1988b). The advantage of this procedure is that, independent of the actual water content at any moment, knowledge of the loss-on-ignition value allows an estimate to be obtained of the water content at field capacity. In the present research work, use could have been made of the actual water contents, as these actual water contents were practically similar to those at field capacity. Since in practical glasshouse horticulture, the soils are not always at field capacity and for that reason estimates of the water content at field capacity are indeed obtained with the aid of loss-onignition values, it was deemed advisable to employ this indirect computation method in the present investigation as well.

The dilution factors, which for the saturation extracts 'field-moist' and 'air-dry' and for the 1:5 extracts will be indicated with the symbols $d_{\mathrm{sf}}, d_{\mathrm{sa}}$ and $d_{\mathrm{w}}$, respectively, were computed with the aid of the following formulas (van den Ende, 1988b):

$$
\begin{aligned}
& d_{\mathrm{sf}}=\frac{3.537 f_{\mathrm{I}}+0.293}{2.617 f_{\mathrm{I}}+0.118} \\
& d_{\mathrm{sa}}=\frac{2.753 f_{\mathrm{I}}+0.273}{2.617 f_{\mathrm{I}}+0.118}
\end{aligned}
$$




$$
d_{\mathrm{w}}=\frac{5}{2.617 f_{\mathrm{I}}+0.118}
$$

in which $f_{\mathrm{l}}$ is the mass fraction loss-on-ignition $\left(600^{\circ} \mathrm{C}\right)$ of oven-dry soil.

For $\mathrm{K}, \mathrm{Na}, \mathrm{Ca}, \mathrm{Mg}, \mathrm{NO}_{3}, \mathrm{Cl}$ and $\mathrm{SO}_{4}$ contents expressed as $\mathrm{mol} \mathrm{m}^{-3}$, the symbols $\mathrm{K}, \mathrm{Na}, \mathrm{Ca}, \mathrm{Mg}, \mathrm{NO}_{3}, \mathrm{Cl}$, and $\mathrm{SO}_{4}$, respectively, will be used, and for EC values expressed as dS $\mathrm{m}^{-1}$ the symbol $E C$. The subscripts $\mathrm{f}$, sf, sa and $\mathrm{w}$ stand for press extract, saturation extract 'field-moist', saturation extract 'air-dry', and 1:5 extract, respectively.

\section{Results and discussion}

\section{Press and saturation extracts}

It stands to reason that dilution factors of saturated pastes have relatively low numerical values. Furthermore, it is known from practical experience that in general for such pastes the factors also vary little among soils, which was experienced in our own investigations as well (van den Ende, 1988a). Consequently, the data on uncorrected ionic concentrations and EC in the saturation extracts (not multiplied with the dilution factors) were in general highly correlated with those of the press extracts, as can be seen in Table 1 .

The correlation coefficients for $\mathrm{EC}, \mathrm{Ca}, \mathrm{Mg}$ and $\mathrm{SO}_{4}$ are somewhat lower than those for $\mathrm{K}, \mathrm{Na}, \mathrm{NO}_{3}$ and $\mathrm{Cl}$. This difference may find its explanation in the finding (paper in preparation) that solid gypsum was present in a large number of the field-moist soil samples. With the addition of water needed to reach saturation, solid gypsum will dissolve partially or entirely and thus will exert a direct influence on the results of the $\mathrm{EC}, \mathrm{Ca}$ and $\mathrm{SO}_{4}$ determinations in the saturation extracts. The results of the $\mathrm{Mg}$ determination will also have been affected by the solubilization of gypsum, since any increase in the quantity of calcium in solution will result in a displacement of a part of adsorbed magnesium by calcium.

Table 1. Regression equations for the relationships between analytical data of press extracts $(y)$ and those of saturation extracts $(x)$. Saturation extracts were prepared from field-moist $\left(x_{\mathrm{sf}}\right)$ or air-dry $\left(x_{\mathrm{sa}}\right)$ soil.

\begin{tabular}{|c|c|c|c|c|c|c|}
\hline \multirow[t]{2}{*}{ Determination } & \multicolumn{3}{|c|}{$y=a x_{\mathrm{sf}}+b$} & \multicolumn{3}{|c|}{$y=a x_{\mathrm{sa}}+b$} \\
\hline & $\mathrm{a}$ & $\mathrm{b}$ & $r$ & $\mathrm{a}$ & $\mathbf{b}$ & $r$ \\
\hline $\mathrm{EC}$ & 1.280 & 1.08 & 0.890 & 1.193 & 1.28 & 0.845 \\
\hline K & 1.320 & -0.05 & 0.965 & 1.261 & 0.90 & 0.936 \\
\hline $\mathrm{Na}$ & 1.359 & 1.48 & 0.954 & 1.259 & 1.49 & 0.927 \\
\hline $\mathrm{Ca}$ & 1.276 & 5.73 & 0.883 & 1.178 & 5.32 & 0.847 \\
\hline $\mathrm{Mg}$ & 1.509 & 1.39 & 0.908 & 1.422 & 1.61 & 0.898 \\
\hline $\mathrm{NO}_{3}$ & 1.558 & 1.83 & 0.931 & 1.418 & 0.69 & 0.909 \\
\hline $\mathrm{Cl}$ & 1.742 & 1.82 & 0.957 & 1.473 & 1.87 & 0.927 \\
\hline $\mathrm{SO}_{4}$ & 1.121 & 5.86 & 0.882 & 1.136 & 3.87 & 0.868 \\
\hline
\end{tabular}


In addition to solid gypsum, solid forms of other salts, such as calcium phosphates and calcium and magnesium carbonates, will have contributed to the occurrence of the above-mentioned difference in correlation coefficients. Due to the lower solubility of the latter salts in comparison with gypsum, such contributions will have been relatively small.

Without exception, the analytical data of the press extracts showed a closer relationship with those of the saturation extracts 'field-moist' than with those of the saturation extracts 'air-dry'. Data which can explain this difference are presented below.

Since the dissolved quantities of $\mathrm{Cl}$ and $\mathrm{NO}_{3}$ are not or only slightly influenced by the degree of dilution of the soil solution, the regression coefficients for these ionic species are large. The smallest regression coefficients were found for $\mathrm{SO}_{4}, \mathrm{Ca}$ and $E C$, which again is associated with dissolution of solid gypsum in the saturation extracts of many of the soil samples. In this connection, it must be remarked that the regression coefficients for $E C$ are not entirely comparable with those for the various ionic species, due to the fact that with increasing ionic concentrations the mobility of the ions decreases somewhat, thus resulting in a reduced contribution of each of the ions to the total EC. For a proper comparison of the regression coefficients for $E C$ with the other coefficients, the former would have to be multiplied by correction factors somewhat larger than one. However, the influence of differences among ionic mobilities in press and saturation extracts on the regression coefficient values for $E C$ was found to be small.

The regression coefficients for $K$ and $N a$ are also relatively small, which can be accounted for by assuming that upon the introduction of water needed to saturate the soil samples portions of the adsorbed potassium and sodium were displaced by calcium and magnesium. Such displacements are normal when a moist soil containing these cations is diluted, even when such a dilution does not result in a solubilization of solid forms of calcium and/or magnesium salts (Bolt et al., 1976).

These displacements of univalent cations by bivalent cations can also serve to account for the finding that the regression coefficients for $\mathrm{Mg}$ are comparatively large. The above-mentioned dissolution of gypsum will have had a lowering effect on the regression coefficients for $\mathrm{Mg}$, since, as said before, the increase in the quantity of calcium in solution will have caused a partial displacement of adsorbed magnesium by calcium. A similar effect, but to a lesser extent, will have resulted from the dissolution of other calcium and/or of magnesium salts.

The regression coefficients in column 5 of Table 1 are as a rule somewhat lower than those in column 2. This is conceivable, on account of the fact that the analytical values of saturation extracts 'air-dry' were in general somewhat higher than those of saturation extracts 'field-moist'. However, the regression coefficient for $\mathrm{SO}_{4}$ in column 5 is slightly higher than that in column 2 . This finding indicates that per unit weight of oven-dry soil the quantities of sulphate withdrawn by the saturation extracts 'air-dry' were generally smaller than those withdrawn by the saturation extracts 'field-moist'. The quantities of sulphate mentioned can be evaluated by multiplying the sulphate contents of the extracts with the mass ratios 'water/solid phase' of the saturated soil pastes from which the extracts were obtained. In this 
way, for the saturation extracts 'air-dry' and 'field-moist' average quantities of 10.9 and $11.8 \mathrm{mmol}$ sulphate per $\mathrm{kg}$ of oven-dry soil, respectively, were calculated. These calculated sulphate quantities will be somewhat higher than the actual mean quantities dissolved in the respective saturated soil pastes, since in the calculation negative adsorption of sulphate ions was not taken into account. However, for the two types of extract the influence of negative adsorption did probably not differ materially, as could be judged from similar calculations of chloride quantities (a mean value of $6.4 \mathrm{mmol}$ chloride per $\mathrm{kg}$ of oven-dry soil was found for both types of extract). The relatively small sulphate quantities withdrawn by the saturation extracts 'airdry' were possibly due to slow dissolution of gypsum precipitated during soil drying or to a decrease in dissolution of gypsum due to the relatively low water contents of the saturated pastes 'air-dry'.

Based on the finding that the potassium concentrations in the saturation extracts 'air-dry' were lower than those in the saturation extracts 'field-moist' (van den Ende, 1989), it was to be expected that the regression coefficient for $K$ in column 5 of Table 1 would be larger than that in column 2. However, the former coefficient is smaller. This aberration will have been caused by the fact that some relationship existed between the potassium concentration in the press extract and the extent of potassium fixation taking place under the influence of soil drying. Potassium fixation was found to be somewhat lower at high than at low potassium concentrations in the press extract. Especially the sandy soils will have contributed to the relationship mentioned, as their press extracts were generally high in potassium, whereas upon drying they fixed only little potassium.

The intercepts for $\mathrm{Ca}$ and $\mathrm{SO}_{4}$ can be considered large and those for $\mathrm{EC}$ and $\mathrm{Mg}$ rather large. The large intercepts for $\mathrm{Ca}$ and $\mathrm{SO}_{4}$ are again to be explained from dissolution of gypsum, which can be expected to have taken place more in soil samples yielding relatively high than in those yielding relatively low concentrations of calcium and sulphate in the press extracts. The relatively large intercepts for $E C$ and $M g$ can also be attributed to dissolution of gypsum, since in the press extracts both the EC values and the magnesium concentrations were correlated with the concentrations of both sulphate ( $r 0.540$ and 0.563 , respectively) and calcium ( $r 0.776$ and 0.532 , respectively).

Although dilution factors of saturated pastes did not vary widely among soils, the variations were large enough to make it worthwhile to multiply the analytical data of the saturation extracts with these dilution factors, before correlation with results obtained with the press extracts were calculated. This inclusion of dilution factors resulted in higher correlation coefficients for $\mathrm{EC}, \mathrm{K}, \mathrm{Na}, \mathrm{NO}_{3}$ and $\mathrm{Cl}$. The regression equations obtained are listed in Table 2.

For $M g$ it was found that the use of dilution factors resulted in nearly no change in the correlation coefficients, whereas for $\mathrm{Ca}$ and $\mathrm{SO}_{4}$ the use of such factors yielded lower correlation coefficients. Again, these findings are to be related to the dissolution of gypsum, which can also be held responsible for the fact that the use of dilution factors for $E C$ resulted in smaller increases in the values of the correlation coefficients than was the case for $\mathrm{K}, \mathrm{Na}, \mathrm{NO}_{3}$ and $\mathrm{Cl}$.

As can be seen from Tables 1 and 2, the use of dilution factors increased the 


\section{J. VAN DEN ENDE}

Table 2. Regression equations for the relationships between analytical data of press extracts $(y)$ and those of saturation extracts multiplied with dilution factors $(x \cdot d)$. Saturation extracts were prepared from field-moist $\left(x_{\mathrm{sf}} \cdot d_{\mathrm{sf}}\right)$ of air-dry $\left(x_{\mathrm{sa}} \cdot d_{\mathrm{sa}}\right)$ soil.

\begin{tabular}{|c|c|c|c|c|c|c|}
\hline \multirow[t]{2}{*}{ Determination } & \multicolumn{3}{|c|}{$y=\mathrm{a} x_{\mathrm{sf}} \cdot d_{\mathrm{s} f}+\mathrm{b}$} & \multicolumn{3}{|c|}{$y=\mathrm{ax} x_{\mathrm{sa}} \cdot d_{\mathrm{sa}}+\mathrm{b}$} \\
\hline & $\mathrm{a}$ & $\mathrm{b}$ & $r$ & a & $\mathrm{b}$ & $r$ \\
\hline $\mathrm{EC}$ & 0.705 & 1.43 & 0.900 & 0.782 & 1.58 & 0.873 \\
\hline $\mathrm{K}$ & 0.719 & 0.44 & 0.976 & 0.818 & 1.21 & 0.973 \\
\hline $\mathrm{Na}$ & 0.833 & 1.03 & 0.977 & 0.964 & 0.35 & 0.977 \\
\hline $\mathrm{NO}_{3}$ & 0.866 & 2.70 & 0.954 & 0.927 & 1.70 & 0.951 \\
\hline $\mathrm{Cl}$ & 1.039 & 1.67 & 0.972 & 1.106 & 0.86 & 0.971 \\
\hline
\end{tabular}

values of correlation coefficients for $\mathrm{EC}, \mathrm{K}, \mathrm{Na}, \mathrm{NO}_{3}$ and $\mathrm{Cl}$, but more strongly so in columns 7 than in columns 4 . These differences in increase will probably be connected with the fact that the ratio 'water content saturated paste 'air-dry'/water content saturated paste 'field-moist' ' (van den Ende, 1988a), and consequently also the ratio $d_{\mathrm{sa}} / d_{\mathrm{sf}}$, depended somewhat on the levels of the water contents of the pastes. The correlation coefficients for $\mathrm{K}, \mathrm{Na}, \mathrm{NO}_{3}$ and $\mathrm{Cl}$ in column 7 of Table 2 are of the same order of magnitude as those in column 4 . The correlation coefficient for $E C$ in column 7, however, is considerably lower than that in column 4 .

The regression coefficients for $E C, K, N a$ and $\mathrm{NO}_{3}$ in Table 2 were found to be smaller than unity. For $E C, K$ and $N a$, this was to be expected on the basis of the factors mentioned in the discussion of the corresponding regression coefficients in Table 1.

The regression coefficients for $K$ in Table 2 are considerably smaller than those for $\mathrm{Na}$, which serves to indicate that during the saturation extraction relatively more potassium than sodium went into solution. This increase in the potassium/sodium ratio in the liquid phase must probably be attributed to the fact that preferential adsorption of potassium by certain clay minerals decreases with decreasing ionic concentrations (van der Molen, 1958; Lagerwerff \& Bolt, 1959; Deist \& Talibudeen, 1967). In contrast with the regression coefficients just mentioned, those for $K$ and $\mathrm{Na}$ in Table 1 differ only a little. In other words, the regression coefficients of the $K_{\mathrm{sf}}$ and $K_{\mathrm{sa}}$ variables (without dilution factors) are relatively large. This finding will have been caused by the fact that some relationship existed between the potassium concentration in the press extract and the dilution of soil solution during the saturation extraction. Especially the sandy soils will have contributed to the relationship mentioned, because, as said already, their press extracts were generally high in potassium, whereas also the dilution factors of their saturation extracts were fairly large.

Based on the consideration that the concentrations of $\mathrm{Cl}$ and $\mathrm{NO}_{3}$ will have been affected by the occurrence of negative adsorption, it was to be expected that the regression coefficients for $\mathrm{Cl}$ and $\mathrm{NO}_{3}$ in Table 2 would be somewhat larger than unity. Such was indeed found for $\mathrm{Cl}$, but for $\mathrm{NO}_{3}$ the coefficients turned out to be smaller than one. This latter finding may be due to chloride interference in the ana- 
lytical determination of nitrate. As a result of this interference, the analytical data for $\mathrm{NO}_{3}$ were partially too low, in particular so for the $\mathrm{NO}_{3}$ data pertaining to the press extracts. Separate investigations on the extent of chloride interference in determinations of nitrate present in known quantities showed that in the press extracts the underestimations of $\mathrm{NO}_{3}$ possibly averaged $3 \mathrm{~mol} \mathrm{~m}^{-3}$, in the saturation extracts $1 \mathrm{~mol} \mathrm{~m}^{-3}$ and in the $1: 5$ extracts $0 \mathrm{~mol} \mathrm{~m}^{-3}$.

The smaller the quantity of water needed to bring a soil from field capacity to saturation, the smaller will be the quantity of sparsely soluble salts, such as gypsum, dissolving as a result of adding water. This difference in quantity of salt will exert an influence on the relationship between the $E C, C a, M g$ and $\mathrm{SO}_{4}$ values of the press extract and those of the saturation extract after multiplication with the dilution factor. For that reason, an attempt was made to correct the relationship between the said variables with the use of a regression calculation in which the dilution factor was included as an extra independent variable.

The influence mentioned above can be particularly high, when sizeable quantities of gypsum are present. For that reason, a measure of the quantity of gypsum present was also included as an independent variable in the regression calculation. The measure chosen was the sulphate content of the saturation extract, multiplied by the dilution factor. For obvious reasons, the resulting value was not usable as extra variable in the regression calculation for $\mathrm{SO}_{4}$. The following equations were obtained:

$$
\begin{aligned}
& E C_{\mathrm{f}}=0.768 E C_{\mathrm{sf}} \cdot d_{\mathrm{sf}}-1.70 d_{\mathrm{sf}}+3.85 \\
& R=0.921 \\
& E C_{\mathrm{f}}=0.856 E C_{\mathrm{sf}} \cdot d_{\mathrm{sf}}-1.90 d_{\mathrm{sf}}-0.0302 S O_{4 \mathrm{sf}} \cdot d_{\mathrm{sf}}+4.32 \quad R=0.929 \\
& R=0.903 \\
& E C_{\mathrm{f}}=0.880 E C_{\mathrm{sa}} \cdot d_{\mathrm{sa}}-1.84 d_{\mathrm{sa}}+3.60 \\
& R=0.914 \\
& E C_{\mathrm{f}}=0.996 E C_{\mathrm{sa}} \cdot d_{\mathrm{sa}}-1.92 d_{\mathrm{sa}}-0.0422 S O_{4 \mathrm{sa}} \cdot d_{\mathrm{sa}}+3.96 \\
& R=0.882 \\
& C a_{\mathrm{f}}=0.756 C a_{\mathrm{sf}} \cdot d_{\mathrm{sf}}-8.52 d_{\mathrm{sf}}+20.13 \\
& R=0.900 \\
& \begin{array}{l}
C a_{\mathrm{f}}=0.984 C a_{\mathrm{sf}} \cdot d_{\mathrm{sf}}-9.44 d_{\text {sf }}-0.238 \\
C a_{\mathrm{f}}=0.870 C a_{\mathrm{sa}} \cdot d_{\text {sa }}-8.48 d_{\mathrm{sa}}+16.40
\end{array} \\
& R=0.863 \\
& C a_{\mathrm{f}}=1.068 C a_{\mathrm{sa}} \cdot d_{\mathrm{sa}}-8.27 d_{\mathrm{sa}}-0.230 S O_{4 \mathrm{sa}} \cdot d_{\mathrm{sa}}+16.87 \\
& R=0.879 \\
& R=0.917 \\
& R=0.913
\end{aligned}
$$

Except for Equation 5, the inclusion of extra variables resulted in higher correlation coefficients. For the relationships between the $E C, C a$ and $M g$ values of press extracts and the corresponding values of saturation extracts 'air-dry', these increases in correlation coefficient were larger than for the relationships between press extracts and saturation extracts 'field-moist'. The inclusion of $d$ variables increased the values of the correlation coefficients more than was the case with inclusion of $\mathrm{SO}_{4} \cdot d$ variables. For $\mathrm{Mg}$, the inclusion of $\mathrm{SO}_{4} \cdot d$ variables was nearly ineffectual. Consequently, for $\mathrm{Mg}$ no equations with these variables are presented. For $\mathrm{SO}_{4}$, no equations with $d$ variables are presented, as the inclusion of these variables yielded lower correlation coefficients than found for the corresponding equations in $\mathrm{Ta}$ ble 1 . 
A possible objection to be raised against the Equations 2, 4, 6 and 8 is that the first and third independent variables were rather highly correlated with each other ( $r 0.638,0.659,0.824$ and 0.775 , respectively). Such correlations may have affected the values of the regression coefficients.

\section{Press and 1:5 extracts}

The correlation coefficients for the relationships between the analytical data of press extracts and those of 1:5 extracts are so low as to make it senseless to present the regression equations for these relationships. The cause of the poor correlation lies mainly in the fact that the dilution factors of the 1:5 suspensions varied strongly among soils.

For the relationships between the analytical data of press extracts and those of 1:5 extracts, multiplied with the dilution factors, the following regression equations were found:

$$
\begin{array}{ll}
E C_{\mathrm{f}}=0.294 E C_{\mathrm{w}} \cdot d_{\mathrm{w}}+3.60 & R=0.752 \\
K_{\mathrm{f}}=0.492 \mathrm{~K}_{\mathrm{w}} \cdot d_{\mathrm{w}}+0.08 & R=0.926 \\
\mathrm{Na}=0.650 \mathrm{Na} a_{\mathrm{w}} \cdot d_{\mathrm{w}}+2.09 & R=0.939 \\
\mathrm{Ca}=0.282 \mathrm{Ca} a_{\mathrm{w}} \cdot d_{\mathrm{w}}+16.63 & R=0.698 \\
M g_{\mathrm{f}}=0.541 \mathrm{Mg}_{\mathrm{w}} \cdot d_{\mathrm{w}}+4.34 & R=0.820 \\
N O_{3 \mathrm{f}}=0.925 \mathrm{NO}_{3 \mathrm{w}} \cdot d_{\mathrm{w}}+3.40 & R=0.940 \\
\mathrm{Cl}=1.174 \mathrm{Cl}_{\mathrm{w}} \cdot d_{\mathrm{w}}+0.79 & R=0.966 \\
S O_{4 \mathrm{f}}=0.232 \mathrm{SO}_{4 \mathrm{w}} \cdot d_{\mathrm{w}}+15.82 & R=0.686
\end{array}
$$

The inclusion of the dilution factors in the equations generally resulted in considerable improvements in the values of the correlation coefficients. Only for $\mathrm{SO}_{4}$, such an inclusion yielded no improvement.

Within the above set of equations, the correlation coefficients for $E C, C a, M G$ and $\mathrm{SO}_{4}$ are lower than those for $\mathrm{K}, \mathrm{Na}, \mathrm{NO}_{3}$ and $\mathrm{Cl}$. Such differences also existed for the two groups of coefficients in the corresponding sets of equations for estimating the chemical composition of a press extract from that of a saturation extract 'field-moist' of 'air-dry' (Table 1), but in these latter cases the differences were considerably smaller. The larger differences in the present case appear to be associated with the fact that here the values for $\mathrm{EC}, \mathrm{Ca}, \mathrm{Mg}$ and $\mathrm{SO}_{4}$ in the aqueous extracts are more strongly influenced by the dissolution of sparsely soluble salts. Gypsum must be seen as a major contributor to this stronger influence, since for most of the soils used more gypsum dissolved in the 1:5 suspensions than in the saturated pastes (paper in preparation). Also other salts, such as calcium phosphates and calcium and magnesium carbonates, will have contributed to this stronger influence, as the high water/soil ratios in the 1:5 suspensions caused relatively large quantities of phosphate and carbonate to go into solution (van den Ende, 1989). The dissolution of these latter salts will have played a relatively larger role in the 1:5 extraction than in the saturation extraction. Nevertheless, in both types of extraction, the dissolution of gypsum will undoubtedly have been the more important factor influencing 
the values of the correlation coefficients for $\mathrm{EC}, \mathrm{Ca}, \mathrm{Mg}$ and $\mathrm{SO}_{4}$.

The unduly low regression coefficients and large intercepts of the equations 11 , 14 and 18 also deserve attention. These findings are again to be related to the strong influence of the dissolution of gypsum and of other sparsely soluble salts. This also holds for the finding that the intercept of Equation 15 is unusually large.

It was observed that the relationships found between $E C$ and $M g$ values of press extracts, on the one hand, and these values of 1:5 extracts, multiplied by the dilution factors, on the other hand, could be corrected for the disturbing influence exerted by the dissolution of gypsum. Such a correction was obtained by constructing regression equations in which two extra independent variables were included, viz. the sulphate content of the 1:5 extract, multiplied by the dilution factor, and the water content of the field-moist soil $\left(w_{\mathrm{f}}\right)$. For a justification of the inclusion of the former variable, reference can be made to what was said about the inclusion of similar variables in Equations 2, 4,6 and 8. The latter variable was included on account of the fact that at higher water content of the soil more gypsum can dissolve in the soil water, which means that with increasing water content at field capacity the value of the correction must decrease. In the calculations, no use was made of the actual water contents of the field-moist soils. Instead, water contents were used that were estimated from loss-on-ignition values (van den Ende, 1988b). The water contents found were expressed as mass ratios 'water/solid phase'.

It must be remarked that inclusion of the water content of the field-moist soil as a variable not only enabled a correction to be made for the dissolution of gypsum but also for the dissolution of other sparsely soluble salts. In comparison with the correction for gypsum, the correction for such other salts will have been slight.

The following equations were obtained:

$$
\begin{array}{lll}
E C_{\mathrm{f}}=0.334 E C_{\mathrm{w}} \cdot d_{\mathrm{w}}+1.25 \mathrm{w}_{\mathrm{f}}+2.60 & R=0.782 \\
E C_{\mathrm{f}}=0.458 \mathrm{EC} C_{\mathrm{w}} \cdot d_{\mathrm{w}}-0.0400 \mathrm{SO}_{4 \mathrm{w}} \cdot d_{\mathrm{w}}+3.08 & R=0.784 \\
E C_{\mathrm{f}}=0.747 E C_{\mathrm{w}} \cdot d_{\mathrm{w}}-0.0886 \mathrm{SO}_{4 \mathrm{w}} \cdot d_{\mathrm{w}}+2.83 \mathrm{w}_{\mathrm{f}}+0.18 & R=0.884 \\
\mathrm{Mg}_{\mathrm{f}}=0.551 \mathrm{Mg}_{\mathrm{w}} \cdot d_{\mathrm{w}}+1.83 \mathrm{w}_{\mathrm{f}}+3.82 & R=0.824 \\
M g_{\mathrm{f}}=0.800 \mathrm{Mg} \cdot d_{\mathrm{w}}-0.0928 \mathrm{SO}_{4 \mathrm{w}} \cdot d_{\mathrm{w}}+4.75 & R=0.868 \\
M g_{\mathrm{f}}=0.816 \mathrm{Mg} \cdot \mathrm{g}_{\mathrm{w}}-0.0943 \mathrm{SO}_{4 \mathrm{w}} \cdot d_{\mathrm{w}}+2.20 \mathrm{w}_{\mathrm{f}}+4.13 & R=0.873
\end{array}
$$

The inclusion of extra variables resulted in higher correlation coefficients. For $E C$, especially the combination of the two extra variables increased the value of the correlation coefficient. For $M g$, mainly the inclusion of the $S O_{4 \mathrm{w}} \cdot d_{\mathrm{w}}$ variable improved the correlation. The correlation coefficients of Equations 21 and 24 are much to very much higher than those obtained in calculations based on the simple regression model (Equations 11 and 15). However, it must be remarked that the $E C_{\mathrm{w}} \cdot d_{\mathrm{w}}$ and $M g_{\mathrm{w}} \cdot d_{\mathrm{w}}$ values were rather highly correlated with the $S O_{4 \mathrm{w}} \cdot d_{\mathrm{w}}$ values ( $r 0.883$ and 0.809 , respectively).

Also for $\mathrm{Ca}$, it was examined whether inclusion of two extra variables, viz. $w_{\mathrm{f}}$ and $S O_{4 \mathrm{w}} \cdot d_{\mathrm{w}}$, in the equation improved the correlation. The correlation coefficients found were indeed somewhat higher than that of Equation 14, but as they 
were still rather low, the equations obtained are not presented. Also for $\mathrm{SO}_{4}$, the inclusion of $w_{f}$, as extra variable, in the equation hardly increased the value of the correlation coefficient.

As the relationships between $C a_{\mathrm{f}}$ and $C a_{\mathrm{w}} \cdot d_{\mathrm{w}}$ and between $S O_{4 \mathrm{f}}$ and $S O_{4 \mathrm{w}} \cdot d_{\mathrm{w}}$ were not linear but somewhat convex curvilinear, it was also examined whether larger increases in the values of correlation coefficients could be obtained by use of an exponential function. Only for $\mathrm{Ca}$, a larger increase in the value of the correlation coefficient was obtained, but here again the improvement in correlation was only small.

It is to be expected that addition of water to a moist soil results in a displacement of adsorbed potassium and sodium by calcium and magnesium, the more so when the resulting dilution causes solid forms of calcium and/or magnesium salts to dissolve. For this reason, it was investigated whether inclusion of the two extra variables in the equations for $K$ and $\mathrm{Na}$ resulted in increases in the values of the correlation coefficients. For $\mathrm{Na}$, such an increase was not observed, thus justifying the conclusion that during the 1:5 extraction dissolution of gypsum and other sparsely soluble salts, resulting from the dilution of the system, hardly affected the quantity of adsorbed sodium.

For $K$, inclusion of the extra variables led to a slight improvement of the value of the correlation coefficient. It is likely, however, that this improvement was not brought about by any factor related to the dissolution of sparsely soluble salts.

Further analysis revealed that the improvement resulted mainly from including water content of the field-moist soil as a variable in the calculations. The effect of this variable on the numerical value of the correlation coefficient is likely to be linked to the fact that the water content of the field-moist soil is related to the quotient 'mass fraction clay $\left(f_{\mathrm{C}}\right) /$ mass fraction loss-on-ignition $\left(f_{\mathrm{l}}\right)$ '. The addition of this quotient as a variable was found to yield a much greater improvement of the correlation coefficient than was the case when water content of the field-moist soil was added as a variable. The following regression equation was obtained:

$$
K_{\mathrm{f}}=0.466 K_{\mathrm{w}} \cdot d_{\mathrm{w}}-1.096 f_{\mathrm{C}} / f_{\mathrm{I}}+2.02 \quad R=0.963
$$

The effect that inclusion of the $f_{\mathrm{C}} / f_{\mathrm{I}}$ quotient as a variable had on the value of the correlation coefficient indicates that in the 1:5 extracts of loamy soils relatively high $K$ values and in the 1:5 extracts of sandy and peaty soils relatively low $K$ values were found. This observation is in agreement with the fact that preferential adsorption of potassium by various clay minerals decreases with decreasing ionic concentrations.

\section{Conclusions and general discussion}

Analytical data of saturation extracts prepared from field-moist soil turned out to be more or less closely correlated with those of press extracts. For $\mathrm{K}, \mathrm{Na}, \mathrm{NO}_{3}$ and $\mathrm{Cl}$, the correlation coefficients ranged from 0.931 to 0.965 , those for electrical conductivity (EC) and $\mathrm{Ca}, \mathrm{Mg}$ and $\mathrm{SO}_{4}$ from 0.882 to 0.908 . Introduction of a correc- 
tion factor, necessitated by variations in the degree of dilution occurring in the preparation of saturated pastes, increased the correlation coefficients for $\mathrm{EC}, \mathrm{K}$, $\mathrm{Na}, \mathrm{NO}_{3}$ and $\mathrm{Cl}$ ( $r$ obtained for $\mathrm{EC} 0.900$ and for $\mathrm{K}, \mathrm{Na}, \mathrm{NO}_{3}$ and $\mathrm{Cl}$ 0.954-0.977). Through introduction of two extra variables, namely the dilution factor and the $\mathrm{SO}_{4}$ content of the saturation extract corrected for the dilution, the correlation coefficients for $\mathrm{EC}, \mathrm{Ca}$ and $\mathrm{Mg}$ could be further increased to $0.929,0.900$ and 0.917 , respectively.

Analytical results obtained from saturation extracts prepared from dried soil were less closely correlated with those obtained from press extracts. However, introduction of a correction factor, depending in value on the volume of water needed to prepare a saturated paste from dry soil in comparison with the volume of water in the field-moist soil, improved the correlation coefficients for $\mathrm{K}, \mathrm{Na}, \mathrm{NO}_{3}$ and $\mathrm{Cl}$ to such an extent that they reached the levels of those obtained with the corrected values of the saturation extracts prepared from field-moist soil.

Analytical data of 1:5 extracts were poorly correlated with those of press extracts. The use of correction factors, being the ratios of water contents of the 1:5 suspensions and those of the field-moist soils, in most cases improved the correlation coefficients considerably. For $\mathrm{K}, \mathrm{Na}, \mathrm{NO}_{3}$ and $\mathrm{Cl}$, the values thus obtained ranged from 0.926 to 0.966 , and for $\mathrm{EC}, \mathrm{Ca}, \mathrm{Mg}$ and $\mathrm{SO}_{4}$ from 0.686 to 0.820 . Through introduction of two additional variables, viz. the water content of the field-moist soil and the corrected $\mathrm{SO}_{4}$ content of the 1:5 extract, the correlation coefficients for $\mathrm{EC}$ and $\mathrm{Mg}$ were further improved to 0.884 and 0.873 , respectively. For $\mathrm{K}$, the correlation coefficient could be further improved to 0.963 through introduction of a variable constituting the ratio of the mass fractions clay and loss-on-ignition.

The correlation coefficients of the relationships obtained are a measure of the precision with which for heavily fertilized soils the chemical composition of the soil solution can be estimated from that of the saturation or the 1:5 extract. They are also a measure of the precision with which the level of nutrient availability for crops can be ascertained (van den Ende, 1989). The correlation coefficients found for the saturation extract relationships are higher than those found for the 1:5 extract relationships. However, for $\mathrm{K}, \mathrm{Na}, \mathrm{NO}_{3}$ and $\mathrm{Cl}$ the differences are only small, and, consequently, for these ionic species the loss of precision resulting from using the 1:5 extract instead of the saturation extract is slight. Against this small loss in precision stands the advantage that for purposes of routine soil testing preparation of the 1:5 extract is less laborious and more practicable than that of the saturation extract.

Based on the assumption that the chemical compositions of soil solutions and saturation extracts are closely correlated, many researchers have used saturation extracts instead of soil solutions in their investigations. It follows from the present study that by doing so errors may be introduced, particularly for $\mathrm{EC}, \mathrm{Ca}, \mathrm{Mg}$ and $\mathrm{SO}_{4}$. Therefore, the soil solutions themselves should preferably be employed for testing the effectiveness of aqueous extracts for an assessment of the availability of nutrients in heavily fertilized soils.

The results obtained with the specific $1: 2$ by-volume extract introduced by Sonneveld \& van den Ende (1971) were also correlated with those obtained with the saturation extract. The correlation coefficients for the ionic concentrations and EC 
proved to be high. The preparation of the $1: 2$ by-volume extract is very practicable. This will be the reason why the extract is already employed in many countries, such as France, Hungary, Japan, Netherlands and Switzerland. However, it remains advisable to calibrate the performance of this method against that of the soil solution method.

An aqueous-extract technique which has already been calibrated against the soil solution method is the $1: 1.5$ by-volume extract introduced by Sonneveld et al. (1974). It is meant for determining the availability of nutrients in potting composts and growing substrates, and is in use as such (Arnold Bik \& Boertje, 1975; Verdure, 1979; von Allmen \& Gysi, 1983; Widmer et al. 1986).

\section{References}

Allmen, F. von \& C. Gysi, 1983. Physikalische und chemische Substratuntersuchungen im Zierpflanzenbau. Gartenbauwissenschaft 48: 171-176.

Arnold Bik, R. \& G. A. Boertje, 1975. Fertilising standards for potting composts based on the 1:1.5 volume extraction method of soil testing. Acta Horticulturae 50: 153-156.

Bolt, G. H., M. G. M. Bruggenwert \& A. Kamphorst, 1976. Adsorption of cations by soil. In: G. H. Bolt \& M. G. M. Bruggenwert (Eds.), Soil Chemistry. Vol. A: Basic Elements, p. 54-90. Elsevier, Amsterdam.

Deist, J. \& O. Talibudeen, 1967. Thermodynamics of K-Ca ion exchange in soils. Journal of Soil Science 18: $138-148$.

Ende, J. van den, 1988a. Water contents of glasshouse soils at field capacity and at saturation. 1. Relationships between water contents. Netherlands Journal of Agricultural Science 36: 265-274.

Ende, J. van den, 1988b. Water contents of glasshouse soils at field capacity and at saturation. 2. Estimating water contents from organic-matter and clay contents or from loss-on-ignition. Netherlands Journal of Agricultural Science 36: 275-282.

Ende, J. van den, 1989. Estimating the chemical composition of the soil solution of glasshouse soil. 1. Compositions of soil solution and aqueous extracts. Netherlands Journal of Agricultural Science 37: 311-322.

Lagerwerff, J. V., \& G. H. Bolt, 1959. Theoretical and experimental analysis of Gapon's equation for ion exchange. Soil Science 87: 217-222.

Molen, W. H. van der, 1958. The exchangeable cations in soils flooded with sea water. Verslagen van Landbouwkundige Onderzoekingen 63.17. Pudoc, Wageningen, $167 \mathrm{pp}$.

Sonneveld, C. \& J. van den Ende, 1971. Soil analysis by means of a 1:2 volume extract. Plant and Soil 35: 505-516.

Sonneveld, C., J. van den Ende \& P. A. van Dijk, 1974. Analysis of growing media by means of a 1:1.5 volume extract. Communications in Soil Science and Plant Analysis 5: 183-202.

Verdure, M., 1979. Standards and interpretation of analytical results for horticultural composts. Acta Horticulturae 99: 231-236.

Widmer, R. E., M. Prasad \& R. R. Marshall, 1986. Peat and bark media nutrient levels in relation to geranium growth and tissue analysis. Journal of the American Society for Horticultural Science 111: 4-8. 